\title{
Human papillomavirus genotype distribution and cervical squamous intraepithelial lesions among high-risk women with and without HIV-I infection in Burkina Faso
}

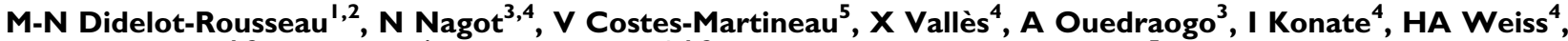 P Van de Perre ${ }^{1,2}$, P Mayaud ${ }^{4}$ and M Segondy ${ }^{*, 1,2}$, for the Yerelon Study Group ${ }^{5}$}

'Department of Virology, Montpellier University Hospital, 34295 Montpellier, France; ${ }^{2}$ Laboratory of Virology, UMR I 45 (University of Montpellier and Institut de Recherche pour le Développement), Saint-Eloi Hospital, 80 Augustin Fliche Ave., 34295 Montpellier Cedex 5, France; ${ }^{3}$ Centre Muraz, BPI 53, Bobo Dioulasso, Burkina Faso; ${ }^{4}$ London School of Hygiene and Tropical Medicine, Keppel Street, London WC IE 7HT, UK; ${ }^{5}$ Department of Pathology, Montpellier University Hospital, 34295 Montpellier, France

\begin{abstract}
Human papillomavirus (HPV) infection and cervical squamous intraepithelial lesions (SILs) were studied in 379 high-risk women. Human papillomavirus DNA was detected in 238 of 360 (66.1\%) of the beta-globin-positive cervical samples, and 467 HPV isolates belonging to 35 types were identified. Multiple (2-7 types) HPV infections were observed in 52.9\% of HPV-infected women. The most prevalent HPV types were HPV-52 (14.7\%), HPV-35 (9.4\%), HPV-58 (9.4\%), HPV-5I (8.6\%), HPV-I6 (7.8\%), HPV-3। (7.5\%), HPV-53 (6.7\%), and HPV-I8 (6.4\%). Human immunodeficiency virus type I (HIV-I) seroprevalence was 36.0\%. Human papillomavirus prevalence was significantly higher in HIV-I-infected women (87 vs 54\%, prevalence ratio (PR) = I.6I, 95\% confidence interval (Cl): I.4- I.8). High-risk HPV types (7। vs 40\%, PR = I.79, 95\% Cl: I.5-2.2), in particular HPV- I6 + I8 (22 vs $9 \%$, PR =2.35, $95 \% \mathrm{Cl}:$ I.4-4.0), and multiple HPV infections (56 vs 23\%, PR $=2.45,95 \% \mathrm{Cl}: 1.8-3.3$ ) were more prevalent in HIV-I-infected women. High-grade SIL (HSIL) was identified in 3.8\% of the women. Human immunodeficiency virus type I infection was strongly associated with presence of HSIL (adjusted odds ratio =17.0; 95\% Cl 2.2-134.I, P=0.007) after controlling for high-risk HPV infection and other risk factors for HSIL. Nine of I 4 (63\%) HSIL cases were associated with HPV-I 6 or HPV-I 8 infection, and might have been prevented by an effective HPV-16/18 vaccine.
\end{abstract}

British Journal of Cancer (2006) 95, 355-362. doi:I0.1038/sj.bjc.6603252 www.bjcancer.com

Published online II July 2006

(c) 2006 Cancer Research UK

Keywords: HPV; genotypes; SIL; HIV-I; Burkina Faso; Africa

Cervical cancer is the most frequent cancer of women in developing countries, particularly in sub-Saharan Africa (Parkin et al, 1999), and it is now well established that genital infection with certain types of human papillomavirus (HPV) causes virtually all cases of cervical intraepithelial neoplasia (CIN) and invasive cervical cancer (ICC) (Walboomers et al, 1999). The HPV types that infect the genital tract have been subdivided into low-risk (LR) types, which are principally found in nonmalignant lesions such as genital warts, and high-risk (HR) types, which are associated with the development of CIN and ICC. Human papillomavirus types $6,11,40,42,43,44,54,61,70,72,81$, and 89 are classified as LR types, whereas types $16,18,31,33,35,39,45$, $51,52,56,58,59,68,73$, and 82 are classified as HR types. In addition, HPV types 26,53, and 66 are considered as probably carcinogenic (Muñoz et al, 2003).

Human papillomavirus prophylactic vaccines are now being developed and promising results have been obtained with

\footnotetext{
*Correspondence: Dr M Segondy; E-mail: m-segondy@chu-montpellier.fr ${ }^{5}$ For more details regarding the Yerelon Study Group, see Appendix A.

Received 24 February 2006; revised 22 May 2006; accepted 12 June 2006; published online II July 2006
}

recombinant L1 capsid protein virus-like particles (VLPs). However, the current HPV vaccines target the most prevalent high-risk HPV (HR-HPV) types worldwide, namely HPV-16 and HPV-18 (Koutsky et al, 2002; Ault et al, 2004; Brown et al, 2004; Harper et al, 2004). It has been shown that crossneutralisation induced by L1 VLPs represents less than $1 \%$ of the neutralising activity induced by the dominant conformational epitope (Combita et al, 2002), indicating that current HPV vaccines would be able to confer only type-specific immunity. Therefore, effectiveness of these vaccines on the prevention of cancer may be lower in populations highly affected by HR-HPV types other than HPV-16 and HPV-18. Thus, it is important to document the distribution of HPV genotypes in HPV-infected women and in women with cervical neoplasia in African countries in order to assess the potential effectiveness of a bivalent HPV-16/18 vaccine.

There have been few detailed studies of HPV genotypes and their association with intraepithelial lesions or ICC in sub-Saharan Africa. Available data suggest, however, a higher prevalence and wider spectrum of oncogenic HPV types compared to studies conducted elsewhere (Castellsague et al, 2001; De Vuyst et al, 2003; Mayaud et al, 2003; Clifford et al, 2005; Wall et al, 2005). Furthermore, the high background prevalence of human immunodeficiency virus type 1 (HIV-1) observed in many African settings adds complexity to our understanding of the epidemiology of HPV 
and cervical neoplasia. Studies conducted in industrialised countries have shown that HIV-1 alters the natural history of HPV infection by upregulating HPV persistence and recurrences, thereby facilitating progression to high-grade lesions and cancer (Sun et al, 1997; Ahdieh et al, 2001; Strickler et al, 2005). Consequently, cervical cancer has been included in the list of AIDS-defining opportunistic conditions by the Centres for Disesase Control and Prevention (Centers for Disease Control and Prevention, 1993). However, the relationships between HIV-1, HPV and squamous intraepithelial lesions (SIL) in sub-Saharan Africa are unclear. Some studies have found no association between HIV-1 and HPV (Mayaud et al, 2001), others found an association between HIV-1 and HPV, but no association between HIV-1 and SIL (De Vuyst et al, 2003), while others found a strong association between HIV-1, HR-HPV, high-grade SIL (HSIL), and cervical cancer (La Ruche et al, 1998; Chirenje et al, 2002; Hawes et al, 2003). Surprisingly, the relentless progression of the AIDS epidemic on the African continent has not been paralleled by increases in cervical cancer rates, in contrast with rates of other AIDS-linked cancers, such as Kaposi's sarcoma or non-Hodgkin's lymphomas (Parkin et al, 1999). This may be due, in part, to a much-reduced life expectancy among HIV-1-infected women in Africa contrasting with a long duration for ICC development. Further understanding of this relationship is essential in order to assess the possible response to a newly introduced HPV-16/18 vaccine in such populations.

In Burkina Faso, a country in West Africa with an estimated HIV-1 prevalence among the general adult population of $4.2 \%$ (http://www.unaids.org), virtually nothing is known of the epidemiology of HPV and HPV-related malignancies, and the impact of HIV on these conditions. The aim of the present study was to determine the prevalence of HPV infection, the distribution of HPV genotypes, the frequency of SIL, and their relationships with HIV-1, in a group of high-risk women in Bobo Dioulasso, the second largest city of Burkina Faso.

\section{MATERIALS AND METHODS}

\section{Study population and sample collection}

We performed a cross-sectional survey nested within the Yerelon cohort study, a research programme that aims to design, implement, and evaluate interventions reducing the risk of HIV-1 and other sexually transmitted infections (STI) among female sex workers (FSWs). The cohort inclusion process has been described elsewhere (Nagot et al, 2002). In brief, FSWs were informally approached at their place of work (streets, bars, or home) through an existing network of trained peer educators, and women were referred to the Centre Municipal d'Hygiene, a public health facility in Bobo Dioulasso. After extensive information and a reflection period of at least 2 weeks, women consenting to participate were invited to answer a standardised questionnaire eliciting information on sociodemographic factors, sexual behaviour, past and current sexual health. Women were examined with a speculum during which genital samples were collected for the diagnosis of vaginal and cervical infections. Blood samples were drawn for HIV, syphilis and Herpes simplex virus type 2 (HSV-2) serologies. Participants were followed up every 4 months with serological re-testing as appropriate.

Between December 2003 and March 2004, consecutive women taking part in the cohort study were requested permission for an additional cervical swab for liquid-based cytology and HPV-DNA detection using a Cervex brush (Cytyc, Montrouge, France). The brush was stirred into a vial of PreservCyt transport solution (Cytyc) and kept at room temperature until shipment to the Pathology Laboratory at the University Hospital, Montpellier, France. The Yerelon Cohort Research Programme has been approved by the Ethical Committee of the Centre Muraz, Bobo Dioulasso, the National Ethical Committee of the Ministry of Health, Burkina Faso, and the Ethics Committee of the London School of Hygiene and Tropical Medicine.

\section{Cervical cytology}

Thin-layer cytological smears were prepared from the Cytic cell suspension vial by controlled membrane transfer technology using the ThinPrep 2000 processor (Cytyc). After Papanicolaou (Pap) staining, slides were independently examined by two senior pathologists who were blinded to all other study results. The 2001 Bethesda classification (Smith, 2002) was used for slide interpretation.

\section{HPV detection and typing}

DNA was extracted from the residual cell suspension as described previously (Gravitt et al, 2000). Samples were tested for the presence of amplifiable DNA and absence of PCR inhibitors by performing beta-globin PCR (Saiki et al, 1988). Two single-step PCRs using consensus primer pairs were performed on the betaglobin-positive samples using first the primer pair MY09/MY11, which allows amplification of a $450 \mathrm{bp}$ fragment in the HPV L1 gene (Manos et al, 1989); negative samples were tested using the primer pair GP5 + /GP6 +, which allows amplification of a $140 \mathrm{bp}$ fragment in L1 (de Roda Husman et al, 1995) and the samples found negative by both MY09/MY11- and GP5 + /GP6 + -mediated single-step PCRs were tested by nested PCR using the primers MY09/MY11 in the first round and the primers GP5 + /GP6 + in the second round. The MY09 primer mixture contained the HPV51-specific HMB01 oligonucleotide as described previously (Gravitt et al, 2000). The amplification mixtures contained $50 \mathrm{pmol}$ of each primer in the presence of $1 \times$ PCR buffer, $6 \mathrm{mM}$ (MY09/MY11 primers), or $4 \mathrm{~mm}(\mathrm{GP} 5+/ \mathrm{GP} 6+$ primers $) \mathrm{MgCl}_{2}, 200 \mu \mathrm{mol}$ (each) dNTPs, $1.5 \mathrm{U}$ of AmpliTaq gold DNA polymerase (Applied Biosystems, Courtaboeuf, France), and $5 \mu \mathrm{l}$ of DNA extract in a volume of $50 \mu \mathrm{l}$. The PCR conditions were $95^{\circ} \mathrm{C}$ for $9 \mathrm{~min}$, followed by 40 cycles of $95^{\circ} \mathrm{C}$ for $1 \mathrm{~min}, 55^{\circ} \mathrm{C}$ (MY09/MY 11 primers) or $38^{\circ} \mathrm{C}$ (GP5 + /GP6 + primers) for $1 \mathrm{~min}$ and $72^{\circ} \mathrm{C}$ for $1 \mathrm{~min}$, and a final extension at $72^{\circ} \mathrm{C}$ for $5 \mathrm{~min}$. For the nested PCR, $2 \mu \mathrm{l}$ of the firstround product were used in the second-round PCR.

HPV typing of the HPV DNA-positive samples was performed using the INNO-LiPA HPV Genotyping v2 test (Innogenetics, Ghent, Belgium). This test is based on the amplification of a part of the L1 region of the HPV genome using the broad-spectrum $\mathrm{SPF}_{10}$-biotinylated primers. Biotinylated amplicons are subsequently hybridised with HPV type-specific oligonucleotide probes, which are immobilised as parallel lines on membrane strips. After hybridisation and stringent washing, streptavidin-conjugated alkaline phosphatase is added and bound to any biotinylated hybrid formed. Incubation with BCIP/NBT chromogen yields a purple precipitate and the results can be visually interpreted (Kleter et al, 1999). This test allows detection of 24 HPV types, namely HR-HPV types $16,18,31,33,35,39,45,51,52,56,58,59$, and 68 , LR-HPV types $6,11,40,42,43,44,54,70$, and 74 , and the probably oncogenic HPV types 53 and 66 .

In addition, HPV typing was performed by sequencing and phylogenetic analyse on HPV DNA-positive samples that could not be typed using the INNO-LiPA Genotyping v2 test. The PCR products obtained using the GP5 + /GP6 + primers were directly sequenced with the BigDye Terminator cycle sequencing kit v3.1 (Applied Biosystems) on the ABI PRISM 3100 genetic analyser (Applied Biosystems); GP5 + and GP6 + primers served as forward and reverse primers, respectively. The nucleotide sequences were aligned and compared with those of known HPV types available through the GenBank database (http://www.ncbi.nlm.nih.gov/) by use of the CLUSTAL W multiple 
sequence alignment program. Phylogenetic trees were constructed by the neighbour-joining method and reliability of the branching orders was assessed by the bootstrap approach with CLUSTAL W. A nucleotide sequence was assigned to a HPV type if it displayed greater than $90 \%$ homology with this type (de Villiers et al, 2004).

\section{Other reproductive tract infection (RTI) or STI}

Vaginal smears were examined microscopically for the presence of Trichomonas vaginalis, Candida spp, and bacterial vaginosis (using the Nugent's score on a Gram-stained smear; Nugent et al, 1991). One cervical swab was cultured onto modified ThayerMartin media plates using standard procedures to detect the presence of Neisseria gonorrhoeae. Molecular diagnosis of Chlamydia trachomatis was not available at the time of the survey, but this infection had been shown to be rare by PCR $(<2 \%)$ in this population (Nagot et al, 2004). Venous blood samples were tested for: HIV-1 and -2 serologies, using a validated national strategy based on two independent ELISA tests (Meda et al, 1999); syphilis serology, by rapid plasma reagin test (RPR, Human $\mathrm{GmbH}$, Wiesbaden, Germany) with reactive sera confirmed by Treponema pallidum haemagglutination assay (TPHA, Newmarket Laboratories Ltd, Kentford, UK); and HSV-2 serology, using a specific gG2-ELISA test (Kalon HSV-2, Kalon Biologicals, Aldershot, UK) proved to have a good sensitivity and specificity on African sera (Van Dyck et al, 2004). CD4 lymphocyte counts were measured from blood samples using a standard flow cytometric method.

\section{Data analysis}

Data were analysed using STATA 8.1 (StataCorp, College Station, TX, USA). Associations between HIV and HPV were assessed with prevalence ratios (PR) and their 95\% confidence intervals (95\% CI). Associations between HSIL and exposures were assessed with odds ratios (OR) and $95 \%$ CI, as HSIL was a rare event, and statistically tested by Fisher's exact test and $\chi^{2}$ for trend where appropriate. Adjusted ORs (AOR) and corresponding 95\% CI were calculated by multiple logistic regression for factors significantly associated with HSIL in univariate analysis (i.e., with $P$-values $<0.1$, or crude $\mathrm{OR} \geqslant 2$ or $<0.5$ ), or for known risk factors for HSIL reported in the literature (e.g., young age at first sex, smoking, hormonal contraception, presence of other STIs, or low CD4 cell count). Associations of prevalence of HPV types with cervical lesions categories were tested by $\chi^{2}$ for trend.

\section{RESULTS}

\section{Study population characteristics, HIV-1, and RTI/STI prevalence}

A total of 379 women were seen during the study period and all agreed to participate. Their median age was 28.0 years (range 16-54 years) and the mean age at first sexual intercourse was 16.7 years. Participants had been involved in commercial sex for a median of 3.2 years, with a median number of 3.3 weekly sexual partners. Condoms were reportedly used in all sexual encounters with first-time clients by $77.1 \%$ of women, but were seldom used with their regular partner. Only $12 \%$ of participants used hormonal contraception and 7\% were current smokers. Prevalence of bacterial vaginosis, C. albicans, and T. vaginalis were $42.4,6.8$, and $9.6 \%$ respectively, and no diagnosis of $N$. gonorrhoeae was made. Only two cases of serological syphilis (RPR- and TPHA-positive sera) were detected. Human immunodeficiency virus type 1 and HSV-2 seroprevalence were 36.6 and $69.8 \%$, respectively.

\section{HPV detection and typing}

Cervical samples were obtained from all 379 women, and 360 $(95.0 \%)$ were positive for beta-globin DNA. The prevalence of cervical HPV was $66.1 \%$ (238 of 360): 114 samples were positive with the MY09/MY11 primer pair, 50 were positive with the GP5 + /GP6 + primer pair, and 74 were positive by nested PCR. Human papillomavirus types could be identified by LiPA in 211 samples and by sequencing in the remaining 27 samples. A total of $467 \mathrm{HPV}$ infections belonging to 35 types were identified (Figure 1). The most prevalent HPV types were HPV-52 (14.7\%), HPV-35 (9.4\%), HPV-58 (9.4\%), HPV-51 (8.6\%), HPV-16 (7.8\%), HPV-31 (7.5\%), HPV-53 (6.7\%), and HPV-18 (6.4\%). Multiple HPV infections (2-7 types) were identified in 126 of $360(35.0 \%)$ women and accounted for $52.9 \%$ (126 of 238 ) of HPV-infected women.

\section{Cervical cytology}

Interpretable cervical smears were obtained from 366 (97\%) women. Squamous intraepithelial lesion were detected in 88 $(24.0 \%)$ women, with $74(20.2 \%)$ being classified as LSIL and 14 $(3.8 \%)$ as HSIL. Thirteen (3.5\%) samples were classified as atypical squamous cells of undetermined significance (ASCUS).

\section{Relationships between HIV-1, HPV infection, and cervical SIL}

A total of 350 women had a complete set of data available, including an interpretable Pap smear, a positive beta-globin DNA PCR and known behavioural and demographic characteristics. Among these women, 126 (36.0\%) were infected with HIV-1 and 30 $(23.8 \%)$ of them had a CD4 cell count $<200$ cells $\mu l^{-1}$. One woman, infected with HIV-2 alone (and infected with HPV-70) was excluded from further analyses. Subsequent analyses are based on the 349 remaining women.

As shown in Table 1, the prevalence of HPV infection was significantly higher in HIV-1-infected women, mainly owing to a higher prevalence of HR-HPV, including HPV types 16 and 18. The prevalence of multiple HPV infection was also increased in HIV-1-infected women. Age-related HPV prevalence according to HIV-1 serostatus is shown in Figure 2. Among HIV-1-seronegative women, HR-HPV infection varied significantly, being more frequent in the younger and older age groups $(P=0.03)$. In contrast, there was no statistically significant association of HPV with age among HIV-1-seropositive women $(P=0.9)$.

Despite the participants' young age, a high prevalence $(24.9 \%)$ of cervical cytological abnormalities was observed (Table 2). As expected, SIL was more prevalent among the HPV-positive women $(P<0.001)$, and among women with multiple HPV infections compared to those infected with a single HPV type (54 of 123 (43.9\%) vs 24 of 109 (22.0\%), P<0.001). Among HPV-infected women, prevalence of SIL was significantly higher among those co-infected with HIV-1 $(P<0.001)$. HSIL was observed exclusively among HPV-infected women, and all but one HSIL cases were observed among HIV-1-infected women $(P<0.001)$ (Table 2$)$. Only HIV-1 infection and HR-HPV types were statistically significantly associated with HSIL in univariate analysis (Table 3), while low CD4 cell count $\left(<200\right.$ cells $\left.\mu l^{-1}\right)$ had an association of borderline significance. None of the classical cofactors of HSIL (e.g., age at fist sex, smoking, presence of other STIs) reported in the literature were associated with HSIL in this study, in part because of the small number of HSIL cases and/or the low prevalence of some of these variables. In multivariate analysis, only HIV-1 infection remained strongly associated with the presence of HSIL $(\mathrm{AOR}=17.0,95 \% \mathrm{CI}: 2.2-134.1, P=0.007)$, while there was suggestion for a nonstatistically significant association between HR-HPV and HSIL (AOR = 7.0, 95\% CI 0.9-55.6, $P=0.07$ ). 


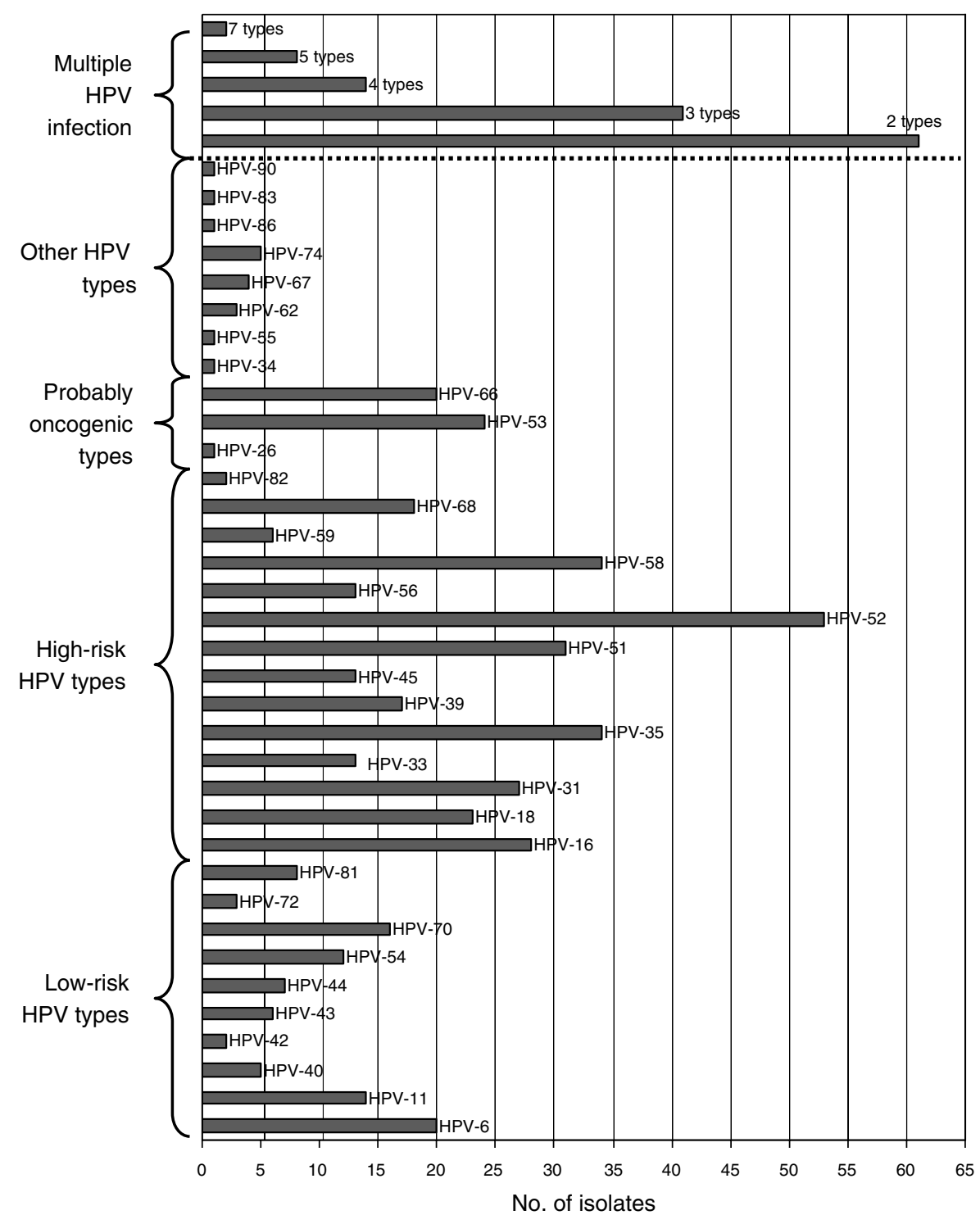

Figure I Distribution of HPV types identified among 349 high-risk women in Bobo-Dioulasso, Burkina Faso.

Table I Infection with high-risk or low-risk HPV types according to HIV-I status, among 349 high-risk women in Bobo Dioulasso, Burkina Faso

\begin{tabular}{lccc}
\hline & \multicolumn{3}{c}{ HIV-I status } \\
\cline { 2 - 4 } HPV types & $\begin{array}{c}\text { Positive (n= I26) } \\
\text { No. (\%) }\end{array}$ & $\begin{array}{c}\text { Negative (n= 223) } \\
\text { No. (\%) }\end{array}$ & Prevalence ratio (95\% Cl) \\
\hline HPV-positive & $110(87)$ & $121(54)$ & $1.61(1.4-1.8)$ \\
At least one high-risk HPV type & $89(71)$ & $89(40)$ & $1.79(1.5-2.2)$ \\
Infection with HPV-16 and/or - 18 & $28(22)$ & $21(9)$ & $2.35(1.4-4.0)$ \\
Low-risk HPV type only & $21(17)$ & $32(14)$ & $1.12(0.8-1.6)$ \\
Multiple HPV infections & $71(56)$ & $51(23)$ & $2.45(1.8-3.3)$ \\
\hline
\end{tabular}

$\mathrm{Cl}=$ confidence interval; $\mathrm{HIV}=$ human immunodeficiency virus; $\mathrm{HPV}=$ human papillomavirus.

To explore the potential impact of a bivalent HPV-16/18 vaccine, we have examined the prevalence of HPV-16- and HPV-18-related infections according to HIV-1 serostatus and cervical lesions categories (Table 4). Human papillomavirus-16 was the most prevalent $(42.9 \%)$ genotype among the 14 women with HSIL, while HPV types 16 or 18 were found in nine $(64.3 \%)$ of these women. All but one woman with HSIL - who was infected with HPV types
54 and 66 - were infected with HPV types belonging to HPV-16- or HPV-18-related phylogenetic groups.

\section{DISCUSSION}

This is the first report of an epidemiological study of cervical HPV and SIL in Burkina-Faso. We did not conduct a general 


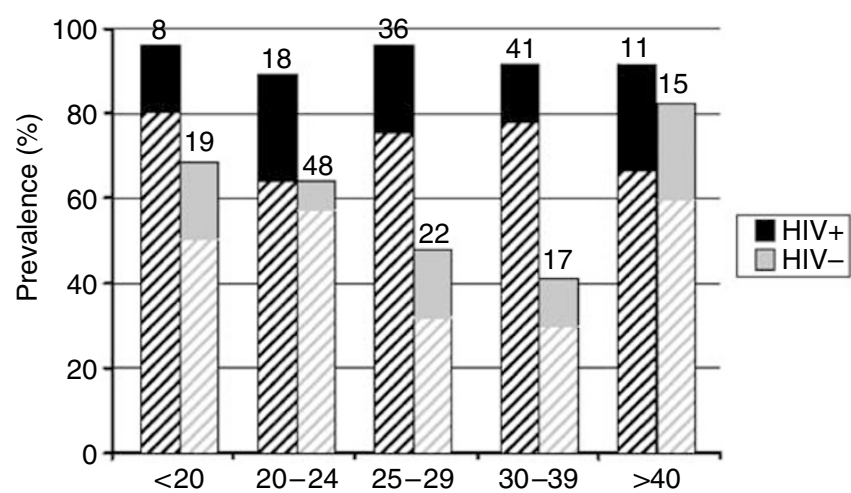

Figure 2 Distribution of HPV infection according to age and HIV-I status among 349 women in Bobo Dioulasso, Burkina Faso. Numbers of women in groups are indicated at the top of bars. The hatched part of the bar represents the proportion of women infected with at least one high-risk HPV type, whereas the unicoloured part represents the proportion of women infected with low-risk HPV types only.

Table 2 Prevalence of SILs according to HPV and HIV-I status among 349 high-risk women in Bobo Dioulasso, Burkina Faso

\begin{tabular}{lccc}
\hline & \multicolumn{3}{c}{ No. (\%) of cervical lesions ${ }^{\mathbf{a}}$} \\
\cline { 2 - 4 } HPV and HIV-I status & LSIL & HSIL & All SIL \\
\hline HPV $-H I V-I-(n=102)$ & $7(6.9)$ & $0(0.0)$ & $7(6.9)$ \\
HPV $-H I V-I+(n=16)$ & $2(12.5)$ & $0(0.0)$ & $2(12.5)$ \\
HPV+ HIV-I- $(n=|2|)$ & $18(14.9)$ & $1(0.8)$ & $19(15.7)$ \\
HPV+ HIV-I+ $(n=\mid 10)$ & $46(41.8)$ & $13(11.8)$ & $59(53.6)$ \\
All $(N=349)$ & $73(20.9)$ & $14(4.0)$ & $87(24.9)$
\end{tabular}

$\mathrm{HIV}=$ human immunodeficiency virus; $\mathrm{HPV}=$ human papillomavirus; $H S I L=$ highgrade SIL; $L S I L=$ low-grade SIL; SIL= squamous intraepithelial lesions. ${ }^{a}$ Atypical squamous cells of undetermined significance (ASCUS) are not included.

population-based study but decided to target a population of highly sexually exposed women. Such women are likely to concentrate the majority of HPV types circulating in the general population of the region, thereby providing some of the information required to assess the usefulness of an HPV vaccine. Moreover, our choice of study population allowed, with an economical sample size, exploration of the relationships between HPV subtypes, presence of SIL, and the role played by HIV in promoting persistence of HPV and progression to HSIL. This is critical information since, ultimately, an HPV vaccine's effectiveness will depend upon the proportion of HSIL and ICC cases attributable to the subtypes included in the vaccine, and possibly the background HIV prevalence in the population, which might act as a catalyst in the upregulation of certain HPV types. Moreover, in some sub-Saharan settings, it is conceivable that HSIL and ICC may disproportionately be found among young HIV-positive women. Thus, although the epidemiological picture found in our study population might not be indicative of infection levels in the general population of Burkina Faso, the diversity of HPV types found and their association with cervical lesions would constitute valid and important data to inform HPV vaccine strategies in the country. Finally, our study represents one of the most detailed and exhaustive molecular studies of HPV in sub-Saharan Africa, which is an important prerequisite in describing HPV epidemiology. Indeed, we detected HPV DNA in cervical samples using the two most commonly used consensus PCR primer sets for genital HPV, namely MY09/MY11 and GP5 + /GP6 + (Qu et al, 1997), and samples found negative by both PCR reactions were tested by nested PCR. Positive HPV samples were typed by LiPA and by sequencing when LiPA was inconclusive, leaving no sample unidentified.

While the epidemiology of genital HPV types has been relatively better studied in Southern and Eastern African countries such as Kenya (Temmerman et al, 1999; De Vuyst et al, 2003), Malawi (Miotti et al, 1996), Mozambique (Castellsague et al, 2001), Tanzania (Mayaud et al, 2003), Uganda (Serwadda et al, 1999), and Zimbabwe (Gravitt et al, 2002; Baay et al, 2004), data from Western Africa have been scarce. The prevalence of HPV infection and associated cervical lesions have been studied in Ivory Coast (La Ruche et al, 1998) and Mali (Bayo et al, 2002), but detailed HPV types were only reported from Senegal (Xi et al, 2003), Nigeria (Thomas et al, 2004), and The Gambia (Wall et al, 2005). Prevalence rates of HPV infection ranging from 13 to $40 \%$ have been reported from low-risk or general populations of sub-Saharan African countries (Miotti et al, 1996; Temmerman et al, 1999; Castellsague et al, 2001; De Vuyst et al, 2003; Mayaud et al, 2003; Xi et al, 2003; Baay et al, 2004; Thomas et al, 2004; Wall et al, 2005). The $66 \%$ prevalence found in the present study, which is still much higher than the $40 \%$ prevalence found in similar highrisk populations in Africa (Kreiss et al, 1992; Langley et al, 1996; Piper et al, 1999), might reflect the high sexual exposure of our study population and, as mentioned earlier, may be attributed in part to the exhaustive nature of our HPV detection strategy. Indeed, the use of a primer pair alone to detect HPV by PCR may be responsible for the underestimation of infections with certain HPV types. For example, HPV types $26,35,42,45,52,54,55,59$, $66,68,73$, and 83 may be missed by using only the MY09/MY11 primer pair (Qu et al, 1997; Gravitt et al, 2000). Human papillomavirus-52, HPV-35, and HPV-58 were the most prevalent types in the present study. A high prevalence of these HPV types has been also observed in other African studies (Gravitt et al, 2000; Castellsague et al, 2001; De Vuyst et al, 2003; Mayaud et al, 2003; Xi et al, 2003; Baay et al, 2004; Thomas et al, 2004; Wall et al, 2005).

The higher HR-HPV prevalence observed in the younger $(<25$ years) and older ( $>40$ years) HIV-1-seronegative women compared to the middle age groups is consistent with high rates of HPV acquisition following entry into sexually active life, and high rates of recurrence or persistence associated with older ages, as described elsewhere (Castle et al, 2005). Although HRHPV infection rates were much higher, there was no statistically significant association with age among the HIV-1-positive women, possibly reflecting the process of upregulation and persistence of HPV elicited by HIV-1, as suggested by others (Palefsky et al, 1999; Ahdieh et al, 2001; Moscicki et al, 2004b), independent of age.

A high prevalence of HIV-1 infection was observed in our study population, and HIV-1 infection was associated with an increased rate of HPV infection, mainly restricted to HR-HPV types. This finding may result from the high level of sexual exposure to both viruses as well as, as mentioned above, from persistence or recurrence of oncogenic HPV following HIV-1 induced immunosuppression. We also found that HIV-1 infection was independently associated with an increase in SIL among HPV-positive women and that HIV-1 represented an important risk factor for the presence of HSIL. These findings are in agreement with other African series (La Ruche et al, 1998; Chirenje et al, 2002; Hawes et al, 2003) and with many studies in industrialised countries (Sun et al, 1997; Ahdieh et al, 2001; Moscicki et al, 2004b; Strickler et al, 2005).

More than half of the HPV-infected FSWs presented multiple HPV infection, which was associated with higher HIV-1 and SIL prevalence. Previous studies have reported a high prevalence of multiple HPV infections among HIV-infected women (Palefsky et al, 1999; Gravitt et al, 2002) which is associated with an increased risk of intraepithelial neoplasia and of cancer (Moscicki et al, 2004a; Herrero et al, 2005). 
Table 3 Univariate analysis: associations between HSIL and sociodemographic, behavioural, and biological factors among 349 high-risk women in Bobo Dioulasso, Burkina Faso

\begin{tabular}{|c|c|c|c|}
\hline Characteristics $^{\mathrm{a}}$ & HSIL/total (\%) (14/349) & Crude OR $(95 \% \mathrm{Cl})$ & $\begin{array}{l}P \text {-value for Fisher's exact test } \\
\text { or for test for trend }\end{array}$ \\
\hline \multicolumn{4}{|l|}{ Sociodemographic factors } \\
\hline Age (years) & $(n=349)$ & & \\
\hline $15-24$ & $0 / 144(0)$ & NC & 0.001 \\
\hline $25-34$ & $9 / 137(7)$ & 1 & 0.09 \\
\hline $35-39$ & $4 / 34(11)$ & $1.67(0.5-5.8)$ & 0.05 \\
\hline$>40$ & $1 / 29(3)$ & $0.49(0.06-4.1)$ & I \\
\hline Parity & $(n=300)$ & & \\
\hline Nulliparous & $1 / 52(2)$ & I & \\
\hline Parity I-3 & $7 / 177(4)$ & $0.48(0.05-4.0)$ & \\
\hline Parity 4+ & $5 / 66(7)$ & $0.26(0.03-2.3)$ & $0.4 *$ \\
\hline \multicolumn{4}{|l|}{ Behavioural factors } \\
\hline Age at first sex (years) & $(n=323)$ & & \\
\hline$>18$ & $2 / 13(15)$ & 1 & \\
\hline $15-18$ & $9 / 207$ (4) & $0.25(0.05-1.3)$ & \\
\hline$\leqslant 15$ & $2 / 103(2)$ & $0.11(0.01-0.9)$ & $0.06 *$ \\
\hline No. years in sex work & $(n=3 \mid i)$ & & \\
\hline$<2$ & $3 / 159(2)$ & 1 & \\
\hline$\geqslant 2$ & $9 / 152(6)$ & $3.27(0.9-12.4)$ & 0.08 \\
\hline Smoking & $(n=348)$ & & \\
\hline No & $13 / 322(4)$ & 1 & \\
\hline Yes & $1 / 26(4)$ & $0.95(0.1-7.6)$ & । \\
\hline \multicolumn{4}{|l|}{ Biological factors } \\
\hline Hormonal contraception & $(n=258)$ & & \\
\hline No & $8 / 211(4)$ & 1 & \\
\hline Yes & $3 / 47(6)$ & $1.73(0.4-6.8)$ & 0.4 \\
\hline HR-HPV types & $(n=349)$ & & \\
\hline Not present & $|/ 17|(0.6)$ & 1 & \\
\hline Present & $13 / 178(7.3)$ & $13.4(1.7-107.1)$ & 0.002 \\
\hline T. vaginalis & $(n=299)$ & & \\
\hline Not present & $10 / 272(4)$ & 1 & \\
\hline Present & $0 / 29(0)$ & NC & 0.6 \\
\hline HSV-2 serology & $(n=347)$ & & \\
\hline Negative & $3 / 106(3)$ & 1 & \\
\hline Positive & ||$/ 24 \mid(4)$ & $1.4(0.4-6.0)$ & 0.6 \\
\hline \multicolumn{4}{|l|}{ HIV-I serology } \\
\hline Negative & 1/223 (0.4) & 1 & \\
\hline Positive & $13 / 126(10)$ & $25.5(3.1-211.1)$ & $<0.001$ \\
\hline CD4 count (in $\mathrm{HIV}+$ ) & $(n=113)$ & & \\
\hline$\geqslant 200$ cells $\left.\mu\right|^{-1}$ & $5 / 86(6)$ & 1 & \\
\hline$<200{\text { cells }\left.\mu\right|^{-1}}^{-1}$ & $5 / 27(19)$ & $3.68(0.9-14.3)$ & 0.06 \\
\hline
\end{tabular}

$\mathrm{Cl}=$ confidence interval; $\mathrm{HIV}=$ human immunodeficiency virus; $\mathrm{HPV}=$ human papillomavirus; $\mathrm{HR}-\mathrm{HPV}=$ high-risk HPV genotypes; HSIL = high squamous intraepithelial lesions; $N C=$ odds ratio $(O R)$ not calculated as cell value $=0$. ${ }^{a}$ Different denominators for some characteristics, depending on questionnaire structure, and some missing data. ${ }^{\text {b }}$ Test for trend.

Table 4 Infection with HPV-I6 and - 8 related types according to HIV-I status and Pap smear result among 349 women in Bobo Dioulasso, Burkina Faso

HIV-I status

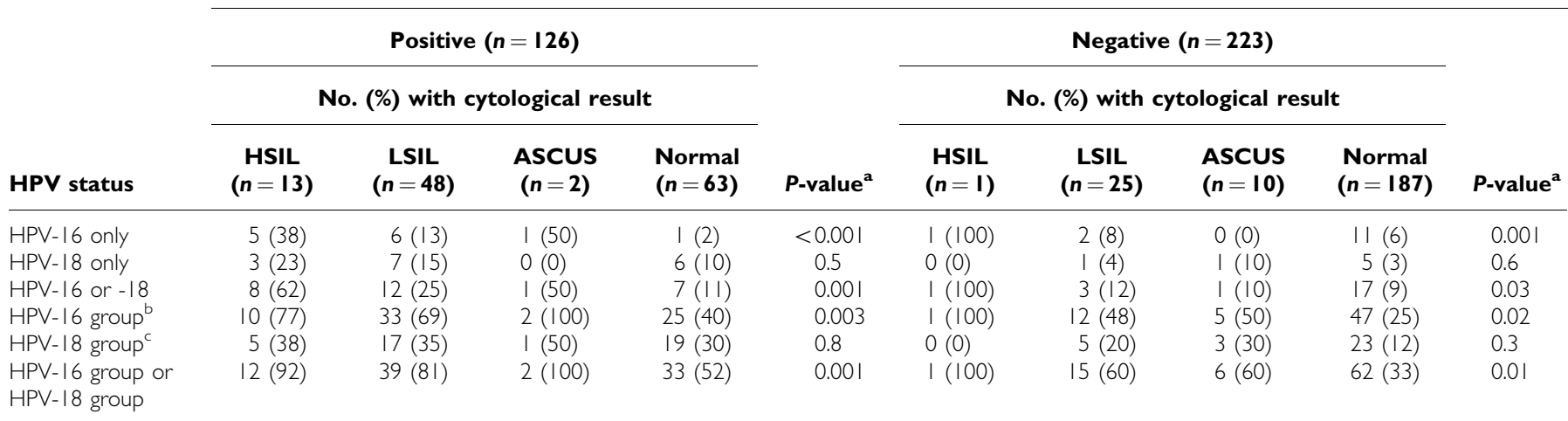

ASCUS = atypical squamous cells of undetermined significance; HIV = human immunodeficiency virus; HPV = human papillomavirus; HR= high-risk types; HSIL = high-grade squamous intraepithelial lesions; $\mathrm{LR}=$ low-risk types; $\mathrm{LSIL}=$ low-grade squamous intraepithelial lesions. ${ }^{a} \chi^{2}$ for trend over cervical abnormalities categories. ${ }^{b} \mathrm{HPV}$ - 16 phylogenetic group includes the following HPV sub-types: 16, 31, 33, 35, 52, 58, and 67. 'HPV-18 phylogenetic group includes the following HPV sub-types: 18, 39, 45, 59, 68, and 70. 
As was found in other African studies (Ter Meulen et al, 1992; Chabaud et al, 1996; La Ruche et al, 1998; Bayo et al, 2002; Kay et al, 2003), HPV-16 and -18 were less common than other HRHPV types overall, but they were involved in $64 \%$ of HSIL lesions, while $93 \%$ of women with HSIL had viruses related to the HPV-16 or HPV-18 phylogenetic groups. Therefore, administration of a bivalent HPV-16/18 vaccine in this population before they get exposed might have the potential to prevent the majority of highgrade lesions in this population, but this would need to be determined in prospective studies. It is not known, however, whether successful control of HPV-16 or -18 might not lead to replacement by other oncogenic HPV types, which are highly prevalent in our population as in many parts of sub-Saharan Africa (Muñoz et al, 2004).

In conclusion, our study confirms the high diversity of HPV genotypes, the burden of HPV-related cervical lesions, the role of HIV-1 as a cofactor of HPV persistent infection, multiple-type infection, and SIL in highly sexually exposed young African women. The potentially preventable nature of prevalent HPV types constitutes a compelling argument to propose HPV-16/18 vaccination to such highly vulnerable populations. However, the safety, immunogenicity and impact of these vaccines in populations with high background HIV-1 prevalence, remain to be determined.

\section{ACKNOWLEDGEMENTS}

We are grateful to the women who participated in this study. The study was supported by grants from the Agence Nationale de Recherches sur le SIDA et les hépatites (ANRS\#1291), France; by the University of Montpellier (01-034 to M-ND-R and MS), France; by the Knowledge Programme on HIV/AIDS and STI of the London School of Hygiene and Tropical Medicine funded by the UK's Department for International Development (DFID); and XV received a fellowship from the Sociedad Española de Infectología y Microbiología Clínica.

\section{REFERENCES}

Ahdieh L, Klein RS, Burk R, Cu-Uvin S, Schuman P, Duerr A, Safaeian M, Astemborski J, Daniel R, Shah K (2001) Prevalence, incidence, and typespecific persistence of human papillomavirus in human immunodeficiency virus (HIV-1)-positive and HIV-1-negative women. J Infect Dis 184: $682-690$

Ault KA, Giuliano AR, Edwards RP, Tamms G, Kim LL, Smith JF, Jansen KU, Allende M, Taddeo FJ, Skulsky D, Barr E (2004) A phase I study to evaluate a human papillomavirus (HPV) type 18 LI VLP vaccine. Vaccine 22: $3004-3007$

Baay MF, Kjetland EF, Ndhlovu PD, Deschoolmeester V, Mduluza T, Gomo E, Friis H, Midzi N, Gwanzura L, Mason PR, Vermorken JB, Gundersen SG (2004) Human papillomavirus in a rural community in Zimbabwe: the impact of HIV-1 co-infection on HPV genotype distribution. J Med Virol 73: $481-485$

Bayo S, Bosch FX, de Sanjose S, Munoz N, Combita AL, Coursaget P, Diaz M, Dolo A, van den Brule AJ, Meijer CJ (2002) Risk factors of invasive cervical cancer in Mali. Int J Epidemiol 31: 202-209

Brown DR, Fife KH, Wheeler CM, Koutsky LA, Lupinaci LM, Railkar R, Suhr G, Barr E, Dicello A, Li W, Smith JF, Tadesse A, Jansen KU (2004) Early assessment of the efficacy of a human papillomavirus type 16 L1 virus-like particle vaccine. Vaccine 22: 2936-2942

Castellsague X, Menendez C, Loscertales MP, Kornegay JR, dos Santos F, Gomez-Olive FX, Lloveras B, Abarca N, Vaz N, Barreto A, Bosch FX, Alonso P (2001) Human papillomavirus genotypes in rural Mozambique. Lancet 358: $1429-1430$

Castle PE, Schiffman M, Herrero R, Hildesheim A, Rodriguez AC, Bratti MC, Sherman ME, Wacholder S, Tarone R, Burk RD (2005) A prospective study of age trends in cervical human papillomavirus acquisition and persistence in Guanacaste, Costa Rica. J Infect Dis 191: $1808-1816$

Centers for Disease Control and Prevention (1993) 1993 revised classification system for HIV-1 infection and expanded surveillance case definition for AIDS among adolescents and adults. JAMA 269: 729-730

Chabaud M, Le Cann P, Mayelo V, Leboulleux D, Diallo AS, Enogat N, Afoutou JM, Anthonioz P, Coll-Seck AM, Coursaget P (1996) Detection by PCR of human papillomavirus genotypes in cervical lesions of Senegalese women. J Med Virol 49: 259-263

Chirenje ZM, Loeb L, Mwale M, Nyamapfeni P, Kamba M, Padian N (2002) Association of cervical SIL and HIV-1 infection among Zimbabwean women in an HIV/STI prevention study. Int J STD AIDS 13: 765-768

Clifford GM, Gallus S, Herrero R, Munoz N, Snijders PJF, Vaccarella S, Anh PTH, Ferreccio C, Hieu NT, Matos E, Molano M, Rajkumar R, Ronco G, de Sanjose S, Shin HR, Suvirach S, Thomas JO, Tunsakul S, Meijer CJ, Franceschi S, IARC HPV Prevalence Surveys Study Group (2005) Worldwide distribution of human papillomavirus types in cytologically normal women in the International Agency for Research on Cancer HPV prevalence surveys: a pooled analysis. Lancet 366: $991-998$

Combita AL, Touze A, Bousarghin L, Christensen ND, Coursaget P (2002) Identification of two cross-neutralizing linear epitopes within the L1 major capsid protein of human papillomaviruses. J Virol 76: 6480-6486 de Roda Husman AM, Walboomers JMM, van den Brule AJC, Meijer CJLM, Snijders PJF (1995) The use of general primers GP5 and GP6 elongated at their $3^{\prime}$ ends with adjacents highly conserved sequences improves human papillomavirus detection by polymerase chain reaction. J Gen Virol 76: $1057-1062$

de Villiers EM, Fauquet C, Broker TR, Bernard HU, zur Hausen H (2004) Classification of papillomaviruses. Virology 324: 17-27

De Vuyst H, Steyaert S, Van Renterghem L, Claeys P, Muchiri L, Sitati S, Vansteelandt S, Quint W, Kleter B, Van Marck E, Temmerman M (2003) Distribution of human papillomavirus in a family planning population in Nairobi, Kenya. Sex Transm Dis 30: 137-142

Gravitt PE, Kamath AM, Gaffikin L, Chirenje ZM, Womack S, Shah KV (2002) Human papillomavirus genotype prevalence in high-grade squamous intraepithelial lesions and colposcopically normal women from Zimbabwe. Int J Cancer 100: 729-732

Gravitt PE, Pleyton CL, Alessi TQ, Wheeler CM, Coutlée F, Hildesheim A, Schiffman MH, Scott DR, Apple RJ (2000) Improved amplification of genital human papillomaviruses. J Clin Microbiol 38: 357-361

Harper DM, Franco EL, Wheeler C, Ferris GG, Jenkins D, Schuind A, Zahaf T, Innis B, Naud P, De Carvalho NS, Roteli-Martins CM, Teixeira J, Blatter MM, Korn AP, Quint W, Dubin G (2004) Efficacy of a bivalent L1 virus-like particle vaccine in prevention of infection with human papillomavirus types 16 and 18 in young women: a randomised controlled trial. Lancet 364: $1757-1765$

Hawes SE, Critchlow CW, Faye Niang MA, Diouf MB, Diop A, Touré P, Kasse AA, Dembele B, Salif Sow P, Coll-Seck AM, Kuyppers JA, Kiviat NB (2003) Increased risk of high-grade cervical squamous intraepithelial lesions and invasive cancer among African women with human immunodeficiency virus type 1 and 2 infections. I Infect Dis 188: $555-563$

Herrero R, Castle PE, Shiffman M, Bratti MC, Hildesheim A, Morales J, Alfaro M, Sherman ME, Wacholder S, Chen S, Rodriguez AC, Burk RD (2005) Epidemiologic profile of type-specific human papillomavirus infection and cervical neoplasia in Guanacaste, Costa Rica. J Infect Dis 191: $1796-1807$

Kay P, Soeters R, Nevin J, Denny L, Dehaeck CMC, Williamson AL (2003) High prevalence of HPV16 in South African women with cancer of the cervix and cervical intraepithelial neoplasia. J Med Virol 71: 265-273

Kleter B, van Doom LJ, Schrauwen L, Molijn A, Sastrowijoto S, ter Schegget J, Lindeman J, ter Harmsel B, Burger M, Quint W (1999) Development and clinical evaluation of a highly sensitive PCR-reverse hybridization line probe assay for detection and identification of anogenital human papillomavirus. J Clin Microbiol 37: 2508-2517

Koutsky LA, Ault KA, Wheeler CM, Brown DR, Barr E, Alvarez FB, Chiacchierini LM, Jansen KU (2002) A controlled trial of human papillomavirus type 16 vaccine. $N$ Engl J Med 347: 1645-1651

Kreiss JK, Kiviat NB, Plummer FA, Roberts PL, Waiyaki P, Ngugi E, Holmes KK (1992) Human immunodeficiency virus, human papillomavirus and cervical intraepithelial neoplasia in Nairobi prostitutes. Sex Transm Dis 19: $54-59$ 
La Ruche G, You B, Mensah-Ado I, Bergeron C, Montcho C, Ramon R, Toure-Coulibaly K, Welffens-Ekra C, Dabis F, Orth G (1998) Human papillomavirus and human immunodeficiency virus infections: relation with cervical dysplasia-neoplasia in African women. Int J Cancer 76: $480-486$

Langley CL, Benga-De E, Critchlow CW, Ndoye I, Mbengue-Ly MD, Kuypers J, Woto-Gaye G, Mboup S, Bergeron C, Holmes KK, Kiviat NB (1996) HIV-1, HIV-2, human papillomavirus infection and cervical neoplasia in high-risk African women. AIDS 10: 413-417

Manos MM, Ting Y, Whright DK, Lewis AJ, Broker TR, Wolinsky SM (1989) Use of polymerase chain reaction amplification for the detection of genital human papillomaviruses. Cancer Cells 7: 209-214

Mayaud P, Gill DK, Weiss HA, Uledi E, Kopwe L, Todd J, ka-Gina G, Grosskurth H, Hayes RJ, Mabey DC, Lacey CJ (2001) The interrelation of HIV-1, cervical human papillomavirus, and neoplasia among antenatal clinic attenders in Tanzania. Sex Transm Infect 77: 248-254

Mayaud P, Weiss HA, Lacey CJ, Gill DK, Mabey DC (2003) Genital human papillomavirus genotypes in northwestern Tanzania. J Clin Microbiol 41: $4451-4453$

Meda N, Gautier-Charpentier L, Soudre RB, Dahourou H, OuedraogoTraore R, Ouangre A, Bambara A, Kpozehouen A, Sanou H, Valea D, Ky F, Cartoux M (1999) Serological diagnosis of human immuno-deficiency virus in Burkina Faso: reliable, practical strategies using less expensive commercial test kits. Bull World Health Organ 77: $731-739$

Miotti PG, Dallabetta GA, Daniel RW, Canner JK, Chiphangwi JD, Liomba GN, Yang L, Shah KV (1996) Cervical abnormalities, human papillomavirus, and human immunodeficiency virus infections in women in Malawi. J Infect Dis 173: 714-717

Moscicki AB, Ellenberg JH, Crowley-Nowick P, Darragh TM, Xu J, Farhat S (2004a) Risk of high-grade squamous intra epithelial lesion in HIV infected adolescents. J Infect Dis 190: 1413-1421

Moscicki AB, Ellenberg JH, Farhat S, Xu J (2004b) Persistence of human papillomavirus infection in HIV-1-infected and -uninfected adolescent girls: risk factors and differences, by phylogenetic types. J Infect Dis 190: $37-45$

Muñoz N, Bosch FX, Castellsague X, Diaz M, de Sanjose S, Hammouda D, Shah KV, Meijer CJLM (2004) Against which human papillomavirus types shall we vaccinate and screen? The international perspective. Int $J$ Cancer 111: 278-285

Muñoz N, Bosch X, de Sanjose S, Herrero R, Castellsague X, Shah KV, Snijders PJF, Meijer CJL (2003) Epidemiologic classification of human papillomavirus types associated with cervical cancer. $N$ Engl J Med 348: $518-527$

Nagot N, Meda N, Ouangre A, Ouedraogo A, Yaro S, Sombie I, Defer MC, Barennes H, Van de Perre P (2004) Review of STI and HIV epidemiological data from 1990 to 2001 in urban Burkina Faso: implications for STI and HIV control. Sex Transm Infect 80: $127-129$

Nagot N, Ouangre A, Ouedraogo A, Cartoux M, Huygens P, Defer MC, Zebika T, Meda N, Van de Perre P (2002) Spectrum of commercial sex activity in Burkina Faso: classification model and risk of exposure to HIV-1. J Acquir Immune Defic Syndr 29: 517-521

Nugent RP, Krohn MA, Hillier SL (1991) Reliability of diagnosing bacterial vaginosis is improved by a standardized method of gram stain interpretation. J Clin Microbiol 29: 297 -301

Palefsky JM, Minkoff H, Kalish LA, Levine A, Sacks HS, Garcia P, Young M, Melnick S, Miotti P, Burk R (1999) Cervicovaginal human papillomavirus

\section{Appendix A}

The Yerelon Study Group is composed of the following persons: Eloi Bahembera, Minata Coulibaly, Marie-Christine Defer, Ramata Diallo, Didier Djagbare, Djeneba Drabo, Issouf Konate, Florent Ky-Dama, Gilles M'Boutiki, Nicolas Meda, Ines Millogo, Nicolas Nagot, Abdoulaye Ouedraogo, François Rouet, Anselme Sanon, Haoua Sawadogo, Roselyne Vallo, and Laurence infection in human immunodeficiency virus-1 (HIV)-positive and highrisk HIV-negative women. J Natl Cancer Inst 91: 226-236

Parkin DM, Pisani P, Ferlay J (1999) Estimates of the worldwide incidence of 25 major cancers in 1990. Int J Cancer 80: 827-841

Piper MA, Severin ST, Wiktor SZ, Unger ER, Ghys PD, Miller DL, Horowitz IR, Greenberg AE, Reeves WC, Vernon SD (1999) Association of human papillomavirus with HIV infection and CD4 cell count in women with high or low numbers of sex partners. Sex Transm Inf 75: $253-257$

Qu W, Jiang G, Cruz Y, Chang CJ, Ho GY, Klein RS, Burk RD (1997) PCR detection of human papillomavirus: comparison between MY09/MY11 and GP5+/GP6+ primer systems. J Clin Microbiol 35: 1304-1310

Saiki RK, Gelfand DH, Stoffel S, Scharf SJ, Higuchi R, Horn GT, Mullis KB, Erlich HA (1988) Primer-directed enzymatic amplification of DNA with a thermostable DNA polymerase. Science 239: 487-491

Serwadda D, Wawer MJ, Shah KV, Sewankambo NK, Daniel R, Li C, Lorincz A, Meehan MP, Wabwire-Mangen F, Gray RH (1999) Use of a hybrid capture assay of self-collected vaginal swabs in rural Uganda for detection of human papillomavirus. J Infect Dis 180: 1316-1319

Smith JH (2002) Bethesda 2001. Cytopathology 13: 4-10

Strickler HD, Burk RD, Fazzari M, Anastos K, Minkoff H, Massad LS, Hall C, Bacon M, Levine AM, Watts DH, Silverberg MJ, Xue X, Schlecht NF, Melnick S, Palefsky JM (2005) Natural history and possible reactivation of human papillomavirus in human immunodeficiency virus-positive women. J Natl Cancer Inst 97: 577-586

Sun XW, Kuhn L, Ellerbrock TV, Chiasson MA, Bush TJ, Wright Jr TC (1997) Human papillomavirus infection in women infected with the human immunodeficiency virus. N Engl J Med 337: 1343 - 1349

Temmerman M, Tyndall MW, Kidula N, Claeys P, Muchiri L, Quint W (1999) Risk factors for human papillomavirus and cervical precancerous lesions, and the role of concurrent HIV-1 infection. Int J Gynaecol Obstet 65: $171-181$

Ter Meulen J, Eberhardt HC, Luande J, Mgaya HN, Chang-Claude J, Mtiro H, Mhina M, Kashaija P, Yu X, Meinhardt G, Gissman L, Pawlita M (1992) Human papillomavirus (HPV) infection, HIV-1 infection and cervical cancer in Tanzania, East Africa. Int J Cancer 51: 515-521

Thomas JO, Herrero R, Omigbodun AA, Ojemakinde K, Ajayi IO, Fawole A, Oladepo O, Smith JS, Arslan A, Munoz N, Snijders PJ, Meijer CJ, Franceschi S (2004) Prevalence of papillomavirus infection in women in Ibadan, Nigeria: a population-based study. Br J Cancer 90: 638-645

Van Dyck E, Buve A, Weiss HA, Glynn JR, Brown DW, De Deken B, Parry J, Hayes RJ (2004) Performance of commercially available enzyme immunoassays for detection of antibodies against Herpes simplex virus type 2 in African populations. J Clin Microbiol 42: 2961-2965

Walboomers JMM, Jacobs MV, Manos MM, Bosch FX, Kummer JA, Shah KV, Snijders PJF, Peto J, Meijer CJLM, Munoz N (1999) Human papillomavirus is a necessary cause of invasive cervical cancer worldwide. J Pathol 189: 12 - 19

Wall SR, Scherf CF, Morison L, Hart KW, West B, Ekpo G, Fiander AN, Man S, Gelder CM, Walraven G, Borysiewicz LK (2005) Cervical human papilloma virus infection and squamous intraepithelial lesions in rural Gambia, West-Africa: viral sequence analysis and epidemiology. Br J Cancer 93: 1068 - 1076

Xi LF, Toure P, Critchlow CW, Hawes SE, Dembele B, Sow PS, Kiviat NB (2003) Prevalence of specific types of human papillomavirus and cervical squamous intraepithelial lesions in consecutive, previously unscreened, West-African women over 35 years of age. Int J Cancer 103: 803-809

Vergne (Centre Muraz, Bobo Dioulasso, Burkina Faso); Jean-Baptiste Andonaba and Adrien Sawadogo (Souro Sanou National Hospital, Bobo Dioulasso, Burkina Faso); Pierre Becquart, Christian Carrière, Vincent Foulongne, Michel Segondy, and Philippe Van de Perre.(Centre Hospitalier Universitaire, Montpellier, France); Philippe Mayaud, Nicolas Nagot, and Helen A Weiss (London School of Hygiene and Tropical Medicine, London, UK). 